\title{
Genetically encoded sensors enable micro- and nano-scopic decoding of transmission in healthy and diseased brains
}

\author{
Li Lin $\mathbb{1}^{1,2} \cdot$ Smriti Gupta $\mathbb{1}^{3} \cdot$ W. Sharon Zheng ${ }^{3,4} \cdot \mathrm{Ke} \mathrm{Si}^{5,6} \cdot$ J. Julius Zhu $\mathbb{1}^{3}$
}

Received: 14 July 2020 / Revised: 6 October 2020 / Accepted: 10 November 2020 / Published online: 4 December 2020

(c) The Author(s) 2020. This article is published with open access

\begin{abstract}
Neural communication orchestrates a variety of behaviors, yet despite impressive effort, delineating transmission properties of neuromodulatory communication remains a daunting task due to limitations of available monitoring tools. Recently developed genetically encoded neurotransmitter sensors, when combined with superresolution and deconvolution microscopic techniques, enable the first micro- and nano-scopic visualization of neuromodulatory transmission. Here we introduce this image analysis method by presenting its biophysical foundation, practical solutions, biological validation, and broad applicability. The presentation illustrates how the method resolves fundamental synaptic properties of neuromodulatory transmission, and the new data unveil unexpected fine control and precision of rodent and human neuromodulation. The findings raise the prospect of rapid advances in the understanding of neuromodulatory transmission essential for resolving the physiology or pathogenesis of various behaviors and diseases.
\end{abstract}

\section{Introduction}

Dysfunction in neural communication is the primary cause of a plethora of psychiatric and neurological disorders. Large genetic association studies implicate that structural and functional alterations in fast transmission mediated by fastacting transmitters, i.e., glutamate and gamma-aminobutyric acid (GABA), may be responsible for a common underlying pathology in many symptomatically distinct cognitive disorders $[1,2]$. Corroborating this view, electrophysiological

Li Lin

linliwz@163.com

1 Department of Neurosurgery, the First Affiliated Hospital of Wenzhou Medical University, Wenzhou 325035, China

2 School of Pharmaceutical Sciences, Wenzhou Medical University, Wenzhou 325035, China

3 Department of Pharmacology, University of Virginia School of Medicine, Charlottesville, VA 22908, USA

4 Biomedical Engineering Class of 2021, University of Virginia School of Medicine, Charlottesville, VA, USA

5 College of Optical Science and Engineering, Zhejiang University, Hangzhou 310027, China

6 School of Brain Science and Brain Medicine, Zhejiang University, Hangzhou 310027, China and other functional studies have identified various aberrant synaptic mechanisms underlying the pathogenesis of diseases $[3,4]$. Neuromodulation research has shown that slow transmission mediated by slow-acting transmitters, such as acetylcholine (ACh), monoamines, and neuropeptides, participates in myriad physiological and pathological processes. Likewise, dysregulation of slow neuromodulatory transmissions is associated with major brain disorders, including addiction, Alzheimer's disease, autism, cardiovascular diseases, depressive disorders and schizophrenia, eating disorders, epilepsy and sleep disorders [5-10]. However, in contrast to research on glutamatergic and GABAergic neurotransmission, delineating synaptic regulation and dysregulation of neuromodulatory transmissions remains a daunting task, which has hampered efforts in mechanistically understanding the neuromodulation-related behaviors and diseases.

The slow advance in defining transmission properties of neuromodulatory communication is due primarily to limitations of currently available tools for monitoring neuromodulatory transmissions. Patch-clamp recordings, which can make reliable repetitive measurements of prominent current responses of fast transmission, serve as the prime method to interrogate fundamental synaptic properties of glutamatergic and GABAergic transmission [11, 12]. However, small and rapidly desensitizing neuromodulatory responses make patch-clamp recordings or electrophysiology ineffective in demarcating synaptic parameters 
of neuromodulatory transmission $[13,14]$. The other currently available neuromodulatory transmission monitoring tools do not work well for this problem, either. For instance, although the detection sensitivity of microdialysis, a frequently employed method, has been improved in recent years, the poor spatial and temporal resolution still limits its ability to assess dynamics of cholinergic and monoaminergic signals $[15,16]$. Fast scan cyclic voltammetry provides excellent nanomolar sensitivity and millisecond temporal resolution, but this detection approach is set back by its poor spatial resolution and inability to distinguish norepinephrine (NE) and dopamine (DA) [17]. Recent effort has led to the development of Förster Resonance Energy Transfer- and cell-based fluorescent ACh and monoamine sensors $[18,19]$. However, the low-sensitivity and/or low-resolution of these sensors permits detection of only volume-size transmission, precluding their application in resolving synaptic properties of neuromodulatory transmission. The limitations, nevertheless, inspire a greater desire to engineer user-friendly and broadly applicable genetically encoded neurotransmitter sensors that permit tissue-specific high-resolution measurements of neuromodulatory transmission $[20,21]$.

\section{Genetically encoded neuromodulatory transmitter sensors}

Recently, colossal collective efforts of tool engineers and biologists yielded several intensity-based genetically encoded sensors for ACh and monoamines (Fig. 1). These sensors consist of a conformationally sensitive circularly permutated GFP (cpGFP) and a ligand-binding protein that alters cpGFP fluorescence by inducing conformational changes upon transmitter binding (Fig. 1A). Two major groups of genetically encoded transmitter sensors were created: G protein-coupled receptor (GPCR)- and bacterial periplasmic binding protein (PBP)-based sensors. GPCRbased sensors, which have the third intracellular loop of primogenitor GPCRs replaced with a cpGFP, frequently inherit the excellent membrane surface trafficking, ligandbinding affinity and pharmacological properties from their primogenitor GPCRs, and are often ready to detect endogenously released transmitters [22, 23]. However, these sensors may have limited dynamics and/or slow kinetics due to the primogenitors' slow kinetics and limited conformational changes associated with ligand binding [2426]. Because PBPs have lower affinities with their ligands, creating the PBP-based sensors with sensitivity matching the endogenous transmitter levels may require painstaking evolution, yet the effort can lead to high-performance sensors with fast kinetics and large dynamics [27-30]. Membrane surface trafficking of the PBP-based sensors can be less than optimal, but these sensors are usually more amenable for targeted expression in other subcellular compartments. Table 1 summarizes the properties of recently developed genetically encoded sensors for ACh and monoamines.

Genetically encoded ACh sensors include GPCR-based $\mathrm{GRAB}_{\mathrm{ACh} 2.0}$ and $\mathrm{GRAB}_{\mathrm{ACh} 3.0}[24,31]$, and PBP-based iAChSnFRs with both green and yellow fluorescent
Fig. 1 High-resolution analysis of genetically encoded sensorillustrated transmission.

A Schematic of G proteincoupled receptor (GPCR)- and bacterial periplasmic binding protein (PBP)-based genetically encoded sensors for neuromodulatory transmitters. B Schematic of viral expression, in vivo and ex vivo applications of genetically encoded sensors. C Schematic of superresolution and/or deconvolution microscopic analysis of image data obtained with genetically encoded sensors. D Threedimensional spatiotemporal profiling of synaptic transmission. Note the collection of exemplary animal experimental data made with the recently published project [32].
A

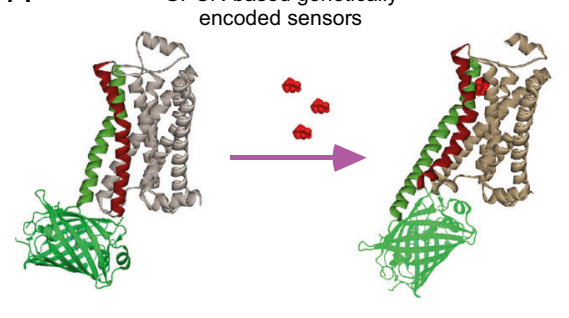

PBP-based genetically encoded sensors
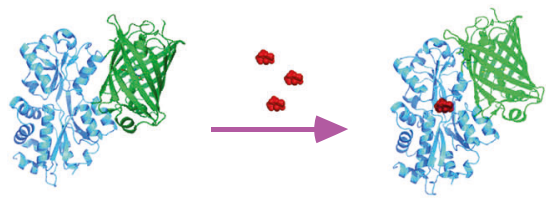

C

Supreresolution and/or deconvolution microscopic analysis

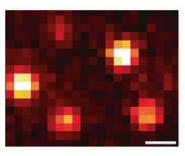

B

Healthy \& diseased animal models
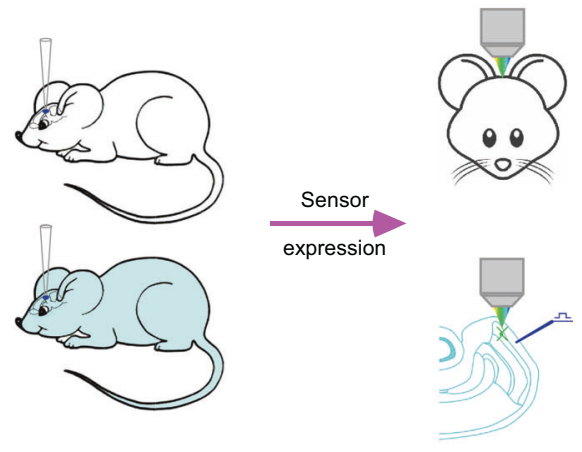

In vivo \& ex vivo experiments

D

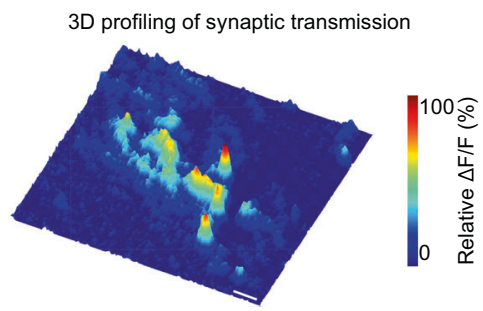


Table 1 Key properties of genetically encoded sensors for acetylcholine and monoamines.

\begin{tabular}{|c|c|c|c|c|c|}
\hline Sensors (ref) & Sensitivity $(\mu \mathrm{M})$ & $\Delta \mathrm{F} / \mathrm{F}(\%)$ & SNR (puff) & Kinetics (ms) & Selectivity \\
\hline \multicolumn{6}{|l|}{ ACh sensors } \\
\hline $\mathrm{GRAB}_{\mathrm{ACh} 2.0}[24]$ & $\mathrm{EC}_{50}=\sim 1-2 \mu \mathrm{M}$ & $\sim 90 \%$ & $\sim 14$ & $\tau_{o n}=\sim 250 \mathrm{~ms} ; \tau_{o f f}=\sim 700 \mathrm{~ms}$ & High \\
\hline $\mathrm{GRAB}_{\mathrm{ACh} 3.0}[31]$ & $\mathrm{EC}_{50}=\sim 2 \mu \mathrm{M}$ & $\sim 280 \%$ & - & $\tau_{o n}=\sim 100 \mathrm{~ms} ; \tau_{\text {off }}=\sim 900 \mathrm{~ms}$ & High \\
\hline iAChSnFR [29] & $K_{\mathrm{d}}=\sim 1 \mu \mathrm{M}$ & $\sim 1200 \%$ & $\sim 50$ & $k_{\mathrm{on}}=0.62 \mu \mathrm{M}^{-1} \mathrm{~s}^{-1} ; k_{\mathrm{off}}=0.73 \mathrm{~s}^{-1}$ & $K_{\mathrm{d}}=\sim 45 \mu \mathrm{M}$ (choline) \\
\hline \multicolumn{6}{|l|}{ NE sensors } \\
\hline GRAB $_{\text {NE1m }}[33]$ & $\mathrm{EC}_{50}=\sim 2 \mu \mathrm{M}$ & $\sim 230 \%$ & $\sim 75$ & $\tau_{\text {on }}=\sim 70 \mathrm{~ms} ; \tau_{o f f}=\sim 700 \mathrm{~ms}$ & $\mathrm{EC}_{50}=\sim 1400 \mu \mathrm{M}(\mathrm{DA})$ \\
\hline $\mathrm{GRAB}_{\mathrm{NE} 1 \mathrm{~h}}[33]$ & $\mathrm{EC}_{50}=\sim 0.1 \mu \mathrm{M}$ & $\sim 130 \%$ & $\sim 10$ & $\tau_{o n}=\sim 35 \mathrm{~ms} ; \tau_{\text {off }}=\sim 2000 \mathrm{~ms}$ & $\mathrm{EC}_{50}=\sim 0.6 \mu \mathrm{M}(\mathrm{DA})$ \\
\hline \multicolumn{6}{|l|}{$5 \mathrm{HT}$ sensors } \\
\hline $\mathrm{GRAB}_{5 \mathrm{HT} 0.5}[34]$ & $\mathrm{EC}_{50}=\sim 0.25 \mu \mathrm{M}$ & $\sim 280 \%$ & $\sim 50$ & $\tau_{\text {on }}=\sim 60 \mathrm{~ms} ; \tau_{\text {off }}=\sim 3300 \mathrm{~ms}$ & High \\
\hline $\mathrm{GRAB}_{5 \mathrm{HT} 1.0}[34]$ & $\mathrm{EC}_{50}=\sim 0.02 \mu \mathrm{M}$ & $\sim 250 \%$ & - & $\tau_{o n}=\sim 200 \mathrm{~ms} ; \tau_{o f f}=\sim 3000 \mathrm{~ms}$ & High \\
\hline iSeroSnFR [35] & $\mathrm{EC}_{50}=\sim 1.5 \mu \mathrm{M}$ & $\sim 1000 \%$ & - & $\tau_{\text {fast }}=\sim 4 \mathrm{~ms} ; \tau_{\text {slow }}=\sim 100 \mathrm{~ms}$ & High \\
\hline DA sensors & $K_{\mathrm{d}}=\sim 350 \mu \mathrm{M}$ & & & & \\
\hline GRAB $_{\text {DA1m }}[25]$ & $\mathrm{EC}_{50}=\sim 0.13 \mu \mathrm{M}$ & $\sim 90 \%$ & - & $\tau_{\text {on }}=\sim 60 \mathrm{~ms} ; \tau_{o f f}=\sim 700 \mathrm{~ms}$ & $\mathrm{EC}_{50}=\sim 1.5 \mu \mathrm{M}(\mathrm{NE})$ \\
\hline GRAB $_{\text {DAlh }}[25]$ & $\mathrm{EC}_{50}=\sim 0.01 \mu \mathrm{M}$ & $\sim 90 \%$ & - & $\tau_{o n}=\sim 140 \mathrm{~ms} ; \tau_{o f f}=\sim 2500 \mathrm{~ms}$ & $\mathrm{EC}_{50}=\sim 0.1 \mu \mathrm{M}(\mathrm{NE})$ \\
\hline $\mathrm{GRAB}_{\mathrm{DA} 2 \mathrm{~m}}[36]$ & $\mathrm{EC}_{50}=\sim 0.1 \mu \mathrm{M}$ & $\sim 340 \%$ & - & $\tau_{o n}=\sim 40 \mathrm{~ms} ; \tau_{\text {off }}=\sim 1300 \mathrm{~ms}$ & $\mathrm{EC}_{50}=\sim 1.2 \mu \mathrm{M}(\mathrm{NE})$ \\
\hline $\mathrm{GRAB}_{\mathrm{DA} 2 \mathrm{~h}}[36]$ & $\mathrm{EC}_{50}=\sim 0.03 \mu \mathrm{M}$ & $\sim 280 \%$ & - & $\tau_{o n}=\sim 50 \mathrm{~ms} ; \tau_{\text {off }}=\sim 7300 \mathrm{~ms}$ & $\mathrm{EC}_{50}=\sim 0.07 \mu \mathrm{M}(\mathrm{NE})$ \\
\hline $\mathrm{rGRAB}_{\mathrm{DA} 1 \mathrm{~m}}[36]$ & $\mathrm{EC}_{50}=\sim 0.1 \mu \mathrm{M}$ & $\sim 150 \%$ & - & $\tau_{\text {on }}=\sim 80 \mathrm{~ms} ; \tau_{\text {off }}=\sim 770 \mathrm{~ms}$ & $\mathrm{EC}_{50}=\sim 2.2 \mu \mathrm{M}(\mathrm{NE})$ \\
\hline $\mathrm{rGRAB}_{\mathrm{DA} 1 \mathrm{~h}}[36]$ & $\mathrm{EC}_{50}=\sim 0.02 \mu \mathrm{M}$ & $\sim 100 \%$ & - & $\tau_{o n}=\sim 60 \mathrm{~ms} ; \tau_{\text {off }}=\sim 2150 \mathrm{~ms}$ & $\mathrm{EC}_{50}=\sim 0.06 \mu \mathrm{M}(\mathrm{NE})$ \\
\hline dLight $_{1.1 / 1.2}[26,37]$ & $K_{\mathrm{d}}=\sim 0.3-0.7 \mu \mathrm{M}$ & $\sim 300 \%$ & - & $\tau_{\text {on }}=\sim 10 \mathrm{~ms} ; \tau_{o f f}=\sim 100 \mathrm{~ms}$ & $K_{\mathrm{d}}=\sim 20 \mu \mathrm{M}(\mathrm{NE})$ \\
\hline dLight $_{1.3}[26,37]$ & $K_{\mathrm{d}}=\sim 2.0 \mu \mathrm{M}$ & $\sim 900 \%$ & - & - & - \\
\hline RdLight $_{1}[41]$ & $K_{\mathrm{d}}=\sim 2.0 \mu \mathrm{M}$ & $\sim 250 \%$ & - & $\tau_{\text {on }}=\sim 15 \mathrm{~ms} ; \tau_{\text {off }}=\sim 400 \mathrm{~ms}$ & $K_{\mathrm{d}}=\sim 20-100 \mu \mathrm{M}(\mathrm{NE})$ \\
\hline
\end{tabular}

versions [29] (Table 1). Directly comparing the perforamance of $\mathrm{GRAB}_{\mathrm{ACh}}$ and $\mathrm{iAChSnFR}$ sensors in the same medial entorhinal cortical preparation revealed a few key differences between these two families of sensors $[29,32]$. Although $\mathrm{GRAB}_{\mathrm{ACh}}$ sensors produced robust fluorescence responses, their inherited slow kinetics significantly attenuated and delayed high-frequency cholinergic signals; they were excellent binary cholinergic signal detectors [24, 31]. iAChSnFRs performed much better in faithfully following cholinergic signals in the entire frequency range $[29,32]$. Although the fluoresence response $\Delta \mathrm{F} / \mathrm{F}$ of $\mathrm{iAChSnFRs}$ is less than optimal, the sensors do have a large dynamic response range for improvement in fluorescence responses [29].

Two GPCR-based norepinephrine (NE) sensors, $\mathrm{GRAB}_{\mathrm{NE} 1 \mathrm{~m}}$ and $\mathrm{GRAB}_{\mathrm{NE} 1 \mathrm{~h}}$, are currently available (Table 1), with GRAB ${ }_{\mathrm{NE} 1 \mathrm{~m}}$ performing better in detecting endogenous adrenergic signals [33]. We expressed iAChSnFR and $\mathrm{GRAB}_{\mathrm{NE} 1 \mathrm{~m}}$ in the same amygdalar preparation to compare their ability in measuring endogenous signals and the results indicated that $\mathrm{GRAB}_{\mathrm{NE} 1 \mathrm{~m}}$ did not rival $\mathrm{iAChSnFR}$ in speed and fluorescence response size [32]. Nevertheless, GRAB ${ }_{\mathrm{NE} 1 \mathrm{~m}}$ could still follow the relatively slower adrenergic transmission ([32]; our unpublished data). These results raise the hope that $\mathrm{GRAB}_{\mathrm{NE} 1 \mathrm{~m}}$ may resolve basic transmission properties of adrenergic modulation, even though the experiments could be technically challenging due to the small adrenergic fluorescence responses [32].

There are both GPCR and PBP-based genetically encoded sensors for serotonin (5-hydroxytryptamine or

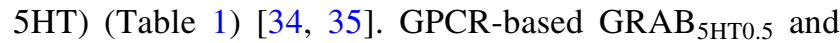
GRAB $_{5 \mathrm{HT} 1.0}$ effectively detected serotonergic signals in populations of cells [34]. GRAB ${ }_{5 \mathrm{HT} 0.5}$ performed better in assessing endogenous single-cell serotonergic signals and could serve as a viable tool for dissecting transmission properties of serotonergic modulation, due presumably to its kinetics and affinity matching more closely to the dynamics and concentration of endogenously released 5HT [32, 34]. The PBP-based iSeroSnFR reported prominent endogenous serotonergic signals in populations of cells [35]. However, given its relatively lower sensitivity (compared to $\mathrm{GRAB}_{5 \mathrm{HT}}$ ) [34, 35], it waits to see whether the sensor can detect single-cell and subcellular serotonergic signals.

Two families of GPCR-based dopamine (3,4-dihydroxyphenethylamine or DA) sensors, human $\mathrm{D}_{2}$ dopamine receptor-based $G_{R A B} B_{D A}[25,36]$ and human $D_{1}$ dopamine receptor-based dLight [26, 37] sensors, are engineered

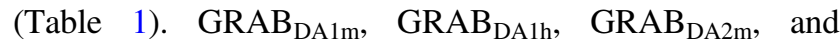
$\mathrm{GRAB}_{\mathrm{DA} 2 \mathrm{~h}}$ are the green versions of genetically encoded DA sensors, while rGRAB ${ }_{\mathrm{DA} 1 \mathrm{~m}}$ and $\mathrm{rGRAB}_{\mathrm{DA} 1 \mathrm{~h}}$ belong to 
the first red versions of genetically encoded neuromodulatory transmitter sensors [25, 36]. dLight sensors also have multiple versions with somewhat different properties $[26,37]$. The top-performing $\mathrm{GRAB}_{\mathrm{DA} 2 \mathrm{~m}}$ and $\mathrm{dLight}_{1}$ registered robust dopaminergic signals from populations of cells in the striatum [32, 36] and basal amygdala [38], which receive the heaviest dopaminergic innervations with probably largest dopaminergic signals [38-40]. A recent addition is a $\mathrm{D}_{2}$ dopamine receptor-based red version of genetically encoded DA sensor, RdLight 1 [41], further expanding the toolbox for DA sensors. Direct experimental comparison showed that $\mathrm{GRAB}_{\mathrm{DA} 2 \mathrm{~m}}$ produced slightly larger single-cell dopaminergic responses with a better signalto-noise ratio compared to $\mathrm{dLight}_{1}$ in the same striatal preparation [32, 36]. While the extremely low baseline dLight $_{1}$ fluorescence often precludes identification of individual expressing cells, $\mathrm{dLight}_{1}$ appears to have slightly higher selectivity over $\mathrm{NE}$ than $\operatorname{GRAB}_{\mathrm{DA} 2 \mathrm{~m}}[26,36]$. It remains unclear whether $\mathrm{GRAB}_{\mathrm{DA} 2 \mathrm{~m}}$ and $\mathrm{dLight}_{1}$ are capable of detecting modest single-cell dopaminergic signals at other brain areas, such as the prefrontal cortex and hippocampus.

\section{A new sensor-based analysis method}

The development of genetically encoded transmitter sensors offers opportunities to make groundbreaking advances in neuromodulation research. While many researchers use the new sensors merely as sensitive detectors to monitor dynamic neuromodulatory signals, as advocated by recent reviews [22, 23, 42, 43], these sensors could actually do more than that. The new genetically encoded neuromodulatory sensors, fortuitously, emit a large amount of photons with their fluorescence responses being largely independent of the expression levels [29, 32-34]. The welcoming properties, when combined with the recent advances of superresolution and/or deconvolution microscopy [44, 45], make it possible to quantify transmission properties of neuromodulation [11], which is essential for demarcating the physiology of behaviors and the pathogenesis of diseases [1-4].

Initial experiments demonstrated that top-performing sensors could resolve synaptic properties of neuromodulatory transmission [29, 32-34]. There are, unfortunately, a significant number of recently published "proof-of-principle" tools or methods that turned out to be biophysically uninterpretable, methodologically unreproducible, and/or biologically inapplicable $[46,47]$. To rigorously introduce this genetically encoded neurotransmitter sensor-based superresolution and deconvolution microscopic analysis method, we here present its biophysical foundation, practical solutions, biological validation, and broad applicability.

\section{Biophysical foundation}

From the 16th to 19th centuries, the trial-and-fail craftsmanship is the primary means to improve microscopic images. In the late 19th century, the Ernst Abbe's arduous computational work, corroborated by experiments carried out in the Carl Zeiss workshop, demonstrated that only knowing the exact light behavior can one gain insight into and control over all decisive factors influencing the microscopic performance [48]. This work led Abbe to conclude that wave optics and diffraction posed fundamental limits on the ability to image, or the Abbe limit of resolution [49]. It gives the minimum distance $\Delta x$ between two distinguishable objects as

$\Delta X_{\text {Abbe }}=\lambda /(2 n \cdot \operatorname{Sin} \alpha) \equiv \lambda / 2 \mathrm{NA}$,

where $n$ gives the index of refraction of the medium in which the image is taken, $\alpha$ is the maximum angle between the optical axis and all rays captured by the microscope objective, and NA stands for numerical aperture used to describe the resolution of microscope.

Later, many researchers revisited the concept of resolution limit, and proposed that in principle, cooperative captivation of many photons could increase resolution beyond the Abbe diffraction limit $[50,51]$. In practice, only in the last $\sim 20$ years, the rapid instrumental and biological advances result in numerous feasible applications, particularly in biology, that routinely surpass of the diffraction limit, a phenomenon termed "superresolution." A number of high-resolution imaging tools including superresolution microscopy, light-sheet microscopy, structured illumination microscopy, confocal microscopy, multiphoton microscopy, deconvolution microscopy, and others, have emerged. Many of them may be classified into two major groups: superresolution microscopy and deconvolution microscopy, where the others are hard to classify into either group because they contain properties of both $[52,53]$.

Through the hardware optimization, superresolution microscopy (e.g., photo-activated localization microscopy, stochastic optical reconstruction microscopy, and stimulated emission depletion microscopy) can achieve excellent resolution improvement with increasing photon counting, following the equation as

$$
\Delta X_{\text {superresolution microscopy }} \sim \Delta X_{\text {Abbe }} \bullet N^{-1 / 2},
$$

where $N$ represents the number of photons detected. This favorable resolution scaling allows superresolution microscopy to fundamentally surpass the classical diffraction limit and reach the sub-100-nm resolution range in most applications, with the possibility of achieving $\sim 10-\mathrm{nm}$ resolution, or down to the single-molecule resolution $[45,52,54]$. The tradeoff of superresolution microscopy 
is imaging speed, particularly in applications of wide-field living imaging that desires high temporal resolution. In addition, superresolution microscopic procedures often discard data from crowded molecules with overlapping images, wasting valuable image information partly degraded by overlapping.

Deconvolution microscopy, which uses computational procedures to improve the quality of microscopic images, can be an excellent alternative for high-resolution living-cell imaging, despite its less favorable resolution scaling as

$\Delta X_{\text {deconvolution microscopy }} \sim \Delta X_{\mathrm{Abbe}} \bullet N^{-1 / 4}$,

The rapidly increased applications of deconvolution microscopy attribute mainly to new genetic tools that yield more collectable photons and expeditiously improved computational algorithms [53, 55, 56]. Given that highperformance genetically encoded neurotransmitter sensors can achieve dense expression of fluorophores and emit large amounts of photons upon transmitter binding, it is possible to achieve wide-field living imaging of transmitter release at the $\sim 100-200-\mathrm{nm}$ resolution and resolve many fundamental synaptic properties of neurotransmission [32]. Of course, the unfavorable $N^{-1 / 4}$ resolution scaling for deconvolution microscopy means that a modest increase in resolution requires a large increase in photon numbers, making the resolution improvement less economically favorable. The combined deconvolution-superresolution microscopic techniques, which may achieve both highresolution and high-imaging speed, are excellent alternative approaches $[57,58]$.

The above-mentioned optical properties predict that genetically encoded neurotransmitter sensors can make reliable measurements of neuromodulatory transmitter releases with nano- and micro-scale spatiotemporal resolution. The measurements may offer reasonably accurate estimations of fundamental synaptic properties of neuromodulatory transmission, such as the transmitter diffusion extent, number of release sites, release pool size, release probability, quantal size, and refilling rate [11, 59]. Defining the synaptic parameters builds the scientific foundation for interrogation of the regulation, function, and short-term and long-term plasticity of neuromodulatory transmission, and sets the neuromodulation baseline for medication testing and development.

\section{Practical solutions}

Following good practical solutions is central to accurate measurements of synaptic properties of neuromodulatory transmission, given particularly that many genetically encoded sensors remain to be optimized to suit them to this task. Selecting the top-performing sensors is the first key step. iAChSnFR, GRAB ${ }_{\mathrm{NE} 1 \mathrm{~m}}$, and $\mathrm{GRAB}_{5 \mathrm{HT} 0.5}$ detected robust but variable single-cell responses in every ex vivo and in vivo neuronal and non-neuronal tissues examined [29, 32-34], supporting their applicability in resolving transmission properties in general tissue preparations ([32]; our unpublished data). GRAB $_{\text {DA2m }}$ and dLight $_{1}$ could achieve the same task in the striatum [25, 26, 32, 36], but might not in the other brain areas ([32]; our unpublished data). The other sensors require further evaluation. Because the existing genetically encoded neuromodulatory transmitter sensors are developed by a very few rigorous research groups, one may deduce the relative performance of sensors generated from the same groups based on the reported sensor specificities (e.g., sensitivity, $\Delta \mathrm{F} / \mathrm{F}, \mathrm{SNR}$, and kinetics) (Table 1).

Expression of genetically encoded transmitter sensors is another key step, which can be achieved with various gene expression approaches, including the frequently employed viral expression systems (e.g., adeno-associated virus (AAV), lenti and Sindbis viruses) (Fig. 1B). Sindbis virus has the most efficient production time of $\sim 1.5$ days, shortest expression time of $\sim 8-24 \mathrm{~h}$, largest payload of up to $15 \mathrm{~kb}$ (ready for co-expression multiple transgenes) and highest expression levels (favored for high spatiotemporal image resolutions), albeit the shortest viable expression time of $\sim 3-5$ days [60-62]. In contrast, several serotypes of AAV viruses have been extensively used due to its minimal toxicity, persistent expression time of $\geq 6$ months (preferred for long-term physiological and behavioral tests), and noninvasive delivery possibility $[63,64]$. However, the small payload for transgene up to $\sim 4.5-5 \mathrm{~kb}$, low viral production efficiency and slow expression time of $\geq 3$ weeks are the major limitations of AAV viruses. Lentivirus, which has relatively faster production, larger payload of up to $\sim 8-10 \mathrm{~kb}$, shorterexpression time of $\sim 1-2$ weeks, and long-lived expression of multiple months [65-67], offers a solution in compromise.

Image acquisition and analysis are the last two key steps. Given the advantages of low instrumental requirement and wide-field living imaging applicability, deconvolution microscopy is practically favored in many biological applications. Since the goal of deconvolution microscopic analysis is to "reassign" the light to its original place, the practical solutions shall focus on correction for image drift and fluctuations, minimization of photobleaching, auto fluorescence, and noise, and optimization of light diffraction correction, many of which are applicable to superresolution microscopy and combined deconvolutionsuperresolution microscopy.

Image drifts and fluctuations can lead to the significant artifactual reassignment of light. Thus, optimizing the 
imaging system to minimize the drift and fluctuations is worth the effort. The electrophysiological setups designed for stable multiple patch-clamp recordings are usually optimized to mitigate the experimental drift and fluctuations $[68,69]$, and they can easily be adapted to acquire stable living-cell images with the minimal drift and fluctuations readily correctable with an intensity-based registration function [32]. Photobleaching and auto fluorescence may result in incorrect estimation of real light intensity distribution and lead to errors in photon reassignment. Running correction algorithms can minimize photobleaching and auto fluorescence $[32,70]$. Noise, a random process responsible for image degradation, comes from two main sources, including photon noise following Poisson distribution and electronic noise in Gaussian nature that is often negligible in modern detectors. Because noise noticeably limits the efficiency of deconvolution algorithms, including denoising procedures at various stages of deconvolution algorithms is highly desired.

Light diffraction through an optical system, which follows the description of its point spread function (PSF), induces optical blur that limits optical resolution. Deblurring is a key process of deconvolution microscopy that uses PSF to reverse optical distortion to "reassign" the light to its original place [71]. Therefore, obtaining the correct PSF, via either theoretical calculation or empirical measurement, is essential for the quality of restored images. Because theoretical PSF models apply only to perfect lenses and welldefined optical paths, and some spherical aberrations are difficult to predict theoretically, empirical measurements are preferred in practice. For accurate determination of an optical system's PSF, it is best to measure PSF at the same system under the same conditions used for the image acquisition. One simple way to obtain PSF is to acquire images of commercially available fluorescent microspheres. In theory, the smallest beads work best. However, small beads are weaker in intensity and bleach more rapidly, and thus, in practice larger beads with a diameter smaller than half the resolution work just fine. To reduce the noise from the empirically measured PSFs, one may average measurements from multiple beads, multiple trials of single beads, and/or multiple circular axes of single beads [32]. It is important to note that deconvolving large datasets of imaging episodes of neuromodulatory transmissions is computationally intensive tasks, taking hours, if not days [32]. Hence, it is wise to employ the optimized and deep learning analysis algorithms to carry out these tasks [44].

\section{Biological validations}

The sensor-based image analysis method has been used to resolve fundamental biological questions, which provides a rigorous validation of its applicability. For example, genetically encoded neurotransmitter sensors, which enable the first high-resolution visualization of spatial diffusion of endogenously released neuromodulatory transmitters [32] (Fig. 1C, D), was employed to resolve a long-standing biological question regarding the primary neuromodulatory transmission mode $[72,73]$. The widely accepted theory of neuromodulatory transmission, proposed three decades ago, postulates that the primary mode of intercellular neuromodulatory communication is volume transmission that takes place among cells in general regions, rather than between specific cells that form direct circuits or contacts $[74,75]$. This model specifically purports that ACh and monoamines diffuse into local areas, affecting many different types of nearby cells, and neuropeptides travel even farther, influencing both local cells and distant cells millimeters away $[74,76]$. The foundation of the theory is based primarily on the assumption that endogenously released neuromodulatory transmitters behave similarly as exogenously applied ones (that diffuse more freely in the extrasynaptic space), which has not yet been corroborated by any direct experimental evidence [72, 73]. Genetically encoded neuromodulatory transmitter sensors, in combination with deconvolution microscopic analysis, permitted the first direct visualization of spatial diffusion of neuromodulatory transmitters at individual release sites, yielding spatial diffusion spread length constants of $\sim 0.75 \mu \mathrm{m}$ for both $\mathrm{ACh}$ and monoamines ([32]; cf. [77-79]) (Fig. 1C, D). Highspeed two-photon imaging technique later verified the value for endogenously released ACh in the intact brain [29]. These results indicate that highly restricted, non-volume neuromodulatory transmission is a key mode for intercellular communication.

Interestingly, the same analysis made with genetically encoded glutamate sensor, iGluSnFR [27], yielded a spread length constant of $\sim 0.60 \mu \mathrm{m}$ for glutamate (Fig. 2A-C) $[32,80]$, a slightly smaller value expected for the negatively charged glutamate electrophoretically influenceable by excitatory currents [81]. Moreover, in combination with new GPCR-based genetically encoded neuropeptide sensors, the analysis allowed the first measurements of neuropeptidergic transmission that disclosed a comparable spread length constant of $\sim 0.80 \mu \mathrm{m}$ (Fig. 2D-F). The identical spatial spread length constants for fast- and slow-acting neurotransmitters across various cells support the notion that synapses optimize their nanoscale pre- and postsynaptic organizational elements (including also the amount of released transmitters, width of synaptic clefts and location of postsynaptic receptors) to maximize efficacy and precision [82-84]. It is attempting to speculate that like the fast-acting neurotransmitters glutamate (e.g., via NMDA receptors) and GABA (e.g., via $\delta$ subunit-containing $\mathrm{GABA}_{\mathrm{A}}$ receptors), neuromodulatory transmitters may employ high affinity receptors and/or cluster releases to 

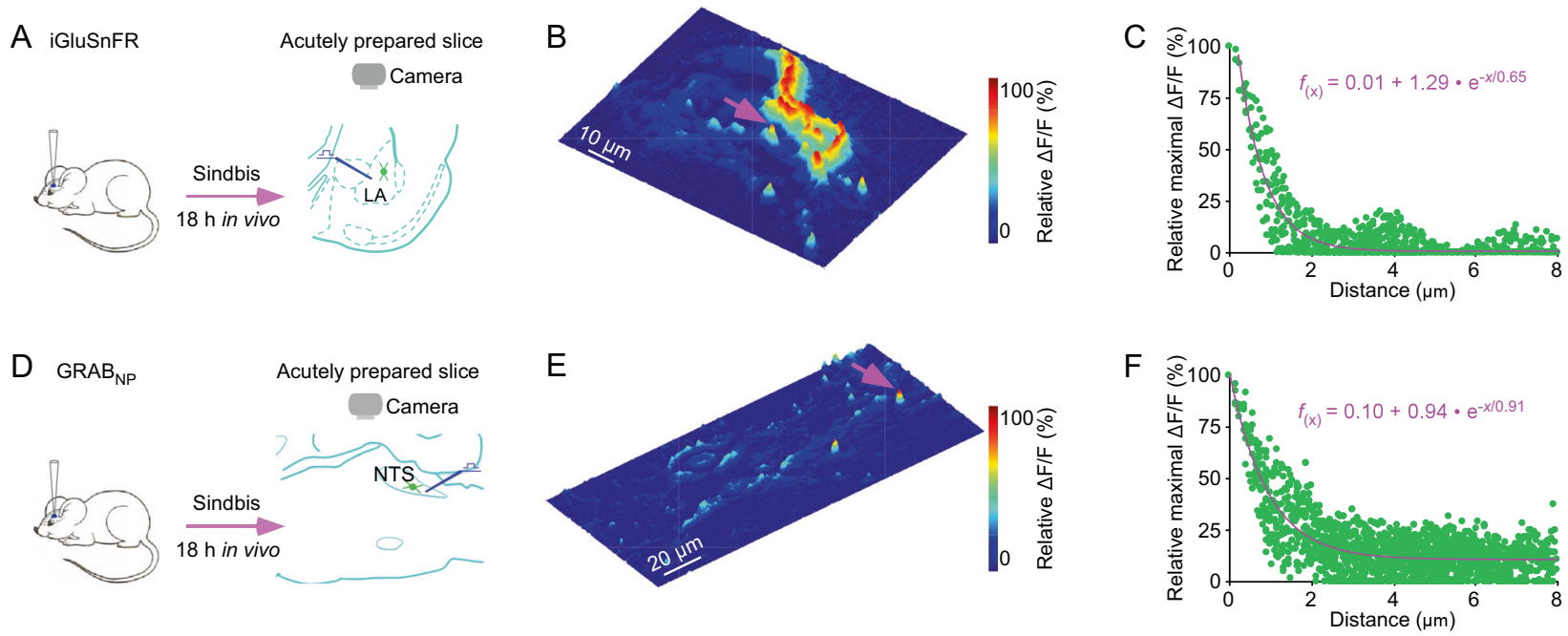

Fig. 2 Visualizing spatial transmitter diffusion with genetically encoded sensors. A Schematic of stimulation-imaging experiments in acute mouse amygdalar slices. LA Lateral amygdala. B Threedimensional spatiotemporal $\Delta \mathrm{F} / \mathrm{F}$ profiling of an iGluSnFR expressing amygdalar neuron to local electrical stimuli. Note one isolated release site indicated by pink arrow in B. C Pixel-wise maximal $\Delta \mathrm{F} / \mathrm{F}$ plot at the isolated release site indicated by the pink arrow in $\mathbf{B}$. Fitting the data points in this plot with a single exponential decay function (pink line) yields an estimated glutamate spread length constant of $0.65 \mu \mathrm{m}$. Note the collection of exemplary animal experimental data made with

achieve certain volume transmission under physiological and pathological conditions. Indeed, accumulating evidence suggests that both fast- and slow-acting neurotransmitters make intercellular communication primarily via highly restricted transmission, with volume transmission serving as a complementary mode under certain conditions $[29,32,72,80]$.

A few top-performing genetically encoded neurotransmitter sensors could reliably follow relatively slow neuromodulatory transmission evoked by moderate (actually, more physiological [11]) rates of stimulation over a prolonged period ([32]; our unpublished data) (Fig. 3A, B). Using the previously established vesicle pool models [8588], one could make reasonably accurate estimations of fundamental neuromodulatory synaptic properties (e.g., release pool size, release probability, and refilling rate). As with the spatial resolution, the temporal resolution of neuromodulatory transmission improves with the increased photon collection. Our preliminary analysis showed that the top-performing genetically encoded neurotransmitter sensors (e.g., iAChSnFR, GRAB ${ }_{\mathrm{NE} 1 \mathrm{~m}}$, and $\mathrm{GRAB}_{5 \mathrm{HT0.5}}$ ) emit sufficient amounts of photons in response to endogenous transmitter releases evoked by prolonged trains of stimuli, permitting determination of basic synaptic properties of neuromodulatory transmission at the microscale resolution (Fig. 3C, D). Combining spatial and temporal analysis might even enable decoding of the number of release sites, release probability and quantal size at individual release the recently published project [32]. D Schematic of stimulationimaging experiments in acute mouse brainstem slices. NTS nucleus tractus solitarius. E Three-dimensional spatiotemporal $\Delta \mathrm{F} / \mathrm{F}$ profiling of an $\mathrm{GRAB}_{\mathrm{NP}}$ expressing NST neuron to local electrical stimuli. Note one isolated release site indicated by pink arrow in E. F Pixel-wise maximal $\Delta \mathrm{F} / \mathrm{F}$ plot at the isolated release site indicated by the pink arrow in E. Fitting the data points in this plot with a single exponential decay function (pink line) yields an estimated neuropeptide spread length constant of $0.91 \mu \mathrm{m}$. Note the collection of exemplary animal experimental data made with the recently published project [32].

sites for neuromodulatory transmission ([59]; for an example, see [29, 32]). The pilot analysis suggests that slow neuromodulatory transmission shares some, but not all properties with fast glutamatergic and GABAergic transmission.

\section{Broad applicability}

The new sensor-based superresolution and/or deconvolution microscopic analysis method has broad applicability in various biological and clinical applications. In particular, the method has revealed unanticipated fine control and precision of neuromodulatory transmission [29, 32], which immediately provide explanations to some puzzling clinical observations and suggest new therapeutics for various psychiatric and neurological disorders, including Alzheimer's disease. For example, the only available therapy for Alzheimer's disease is based on the finding of diminishing ACh release and deteriorating cholinergic neurons in Alzheimer's brains-the cholinergic hypothesis [89]. Currently, all FDA-approved Alzheimer's drugs directly or indirectly inhibit acetylcholinesterase to boost cholinergic signals. These medicines have limited efficacy in cognitive improvement, and upon medication termination, induce irreversible, accelerated deterioration [90, 91]. The fine spatiotemporal control of cholinergic transmission illustrated by genetically encoded sensors sheds light on these two clinical observations [29, 32]. First, 

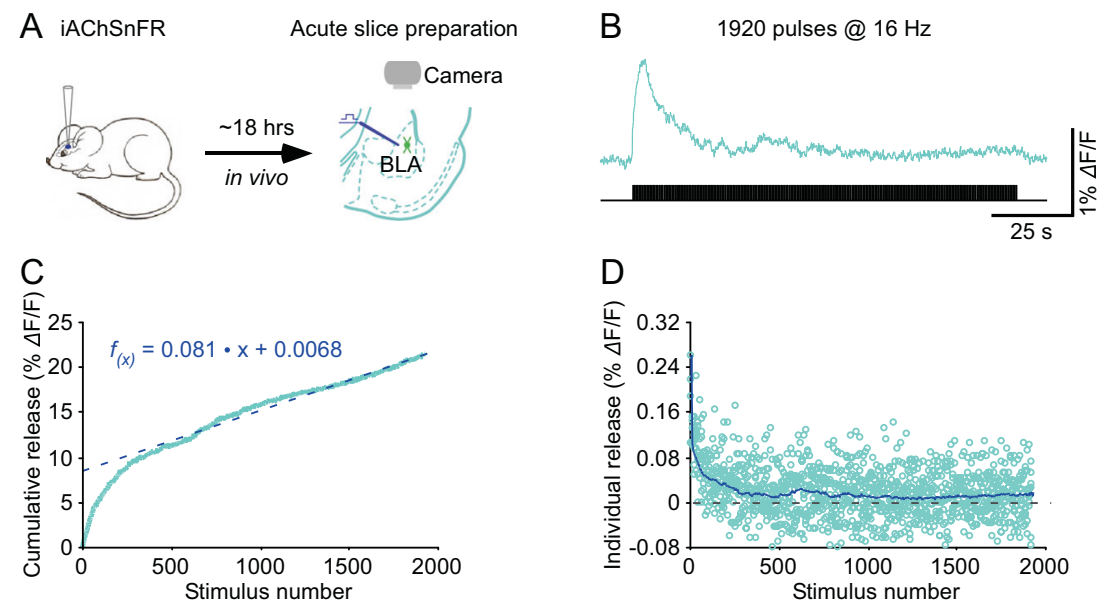

Fig. 3 Decoding cholinergic synaptic properties with genetically encoded sensor iAChSnFR. A Schematic of stimulation-imaging experiments in ex vivo mouse basolateral amygdala (BLA) preparation. B Fluorescence responses of an iAChSnFR expressing amygdalar neuron evoked by a prolonged train of 1920 stimulating pulses at 16 Hz. Plots of cumulative (C) and individual (D) releases against stimulus numbers enable estimations of the readily releasable pool size, refilling rate, release probability of cholinergic synapses at the

acetylcholinesterase inhibitors could reduce the physiological precision of cholinergic transmission (cf. [72, 73]), explaining the limited cognitive improvement. Second, long-term application of acetylcholinesterase inhibitors might homeostatically upregulate acetylcholinesterase levels in Alzheimer's patients and/or downregulate presynaptic ACh release [91], explaining the accelerated deterioration upon medication termination.

Similarly, dysregulated adrenergic transmission often appears as an early pathological correlate of cognitive decline in Alzheimer's disease [92, 93]. Genetically encoded sensors revealed a surprising set of adrenergic synaptic properties seemingly designed to run counter to the natural tendency of synapses to achieve fine-tuned linear inputoutput computation ([32]; our unpublished data). These properties distinguish adrenergic transmission from all other neuronal transmissions, including the fast glutamatergic and GABAergic transmission [12], and other slow neuromodulatory transmission $[29,32]$. The findings underscore the unique contribution of adrenergic transmission to finetuning of attention [94], optimization of behavior in complex social and physical environments [95], and impairment of complex mental tasks (e.g., reasoning and abstract thinking) in Alzheimer's patients [96].

Addiction, a leading health problem that results in multiple millions of human disability every year, represents a complex reinforcement behavior manifested by compulsive substance use despite harmful consequence [97]. Addictive disorders involve primary disturbances of the dopaminergic system, although the significance of non-dopaminergic

amygdalar neuron. Note in $\mathbf{C}$ a straight cyan line $\left(f_{(\mathrm{x})}=0.081 \bigcirc x+\right.$ 0.0068 ) fitted to the late points of blue cumulative trace with its $y$-axis intercept and slope taken as the pool estimate and vesicle refill rate, respectively, and in $\mathbf{D}$ cyan trace representing averages of blue individual releases, corresponding to the release probability. Note the collection of exemplary animal experimental data made with the recently published project [32].

systems, which has been less understood, should not be underestimated [8, 10,97]. Addictive behavior consists of attention, motivation, and learning processes, which seem to be differentially regulated by distinct local subcellular and rapid subsecond dopaminergic signals [98]. A major weakness of the extant literature is that no study to date has been able to capture the behavior-relevant rapid cell- and subcellular-specific dopaminergic signal dynamics. Genetically encoded DA sensors can (at least in the striatum) qualify dynamics of individual dopaminergic releases with microscopic spatiotemporal resolution [32], and subsequently define synaptic parameters and alternations responsible for specific addictive behavioral events. The insights gained from addictive research should also benefit the understanding of several other related psychiatric and neurological disorders, such as Parkinson's disease, Huntington's disease, Tourette's syndrome, attention-deficit/ hyperactivity disorder, and schizophrenia [8].

Stress and adversity responses initiate coordinated neuromodulatory actions at a variety of brain areas to alter attention, anxiety, emotion, pleasure, award, aversion, motor, executive and other behavioral processes, and maladaptive responses may result in melancholic and atypical depressions $[99,100]$. Depression affects about one in six individuals in their lifetime and currently, more than 300 million people around the world [99, 101]. The early clinical observation leads to the monoamine hypothesis of depression positing that depressive disorders are due to the decreased monoamines [102]. Today, the monoamine-based antidepressants remain the first line of therapy for 
depression, yet the treatments have slow onset, low rate of response and low rate of remission (about 30\%) as the mechanisms of their action remain elusive [99, 100]. Recent advances in genetic profiling, circuit analysis, and animal model development have unveiled many insights of stress responses and depression, highlighting the heterogeneous subtypes of monoaminergic neurons and circuits involved in various stress and depressive behavioral processes [103, 104]. However, limitations of electrophysiological approach have so far hampered efforts in functionally linking specific transmission changes in specific monoaminergic neurons and circuits with particular stress and depressive behavioral episodes [104]. Genetically encoded neuromodulatory transmitter sensors make it possible to directly delineate specific synaptic alterations of monoaminergic transmission at specific monoaminergic axonal termini of specific subtypes of neurons in specific neuronal circuits [32]. Such analysis should shed new lights on stress responses and depressive disorders.

Sleep is one of the most mysterious yet ubiquitous animal behaviors, and sleep disorders, the most common clinical problems, cause a variety of healthy issues including depression, cognitive decline, immune deficiencies, and obesity [105-107]. ACh and monoamines play complex and central roles in regulation of sleep-wake behaviors. While the early studies reported that neurons in the cholinergic nuclei are essential for initiating and maintaining wakefulness [108, 109], the late results attributed the role in part to glutamatergic neurons in the nuclei. It is still in debate whether cholinergic neurons are necessary for wakefulness [105]. Genetically encoded ACh sensors detected the neuronal activity-evoked large initial and small, sustained ACh releases from cholinergic neurons [29, 32]; these sensors allowed direct assessment of synaptic properties of cholinergic transmission at natural sleep-wake cycles to define cholinergic contributions [105, 106]. Coerulear neurons are not required for wakefulness, but rather crucial for promoting wakefulness under certain conditions [95]. Adrenergic transmission illustrated by genetically encoded NE sensors appeared to operate against the natural tendency of synapses to make a linear input-output computational process ([32]; our unpublished data), ideally for finely tuning wakefulness and attention [94]. This operation, however, would render adrenergic transmission to be vulnerable to system runaway. Adrenergic synapses seem to set a small release pool and a tiny refill rate to ensure neurotransmitter depletion after a certain amount of neuronal activity to create an emergency breakpoint ([32]; our unpublished data), which is presumably responsible for the observed behavioral arrests [94]. Obviously, a comprehensive analysis with genetically encoded NE sensors should demarcate the synaptic mechanisms of adrenergic involvements in sleep-wake cycles and sleep disorders.
Serotonergic and dopaminergic roles in sleep-wake cycles are even less clear. Although some reports suggested that 5HT might initiate and maintain sleep, the others found that serotonergic neurons promoted wake, reflecting presumably the primary and secondary effects of a large variety of serotonergic processes [105, 106]. Defining synaptic alterations of serotonergic transmission at natural sleep-wake cycles with genetically encoded 5HT sensors should provide new insights into serotonergic roles in sleepwake behaviors [34]. DA is involved in regulation of sleep and wakefulness in a way similar to its other reinforcers (e.g., food, water, and sex) because dopaminergic neuronal activity and extracellular DA levels correlate with circadian oscillations and sleep-orienting behaviors [110, 111]. However, how DA regulates and/or is regulated by the circadian clock and other sleep-wake regulators remain elusive due to the modest DA release changes and varied dopaminergic effects in the midbrain, hypothalamus, and other related brain areas, underlining the importance of decoding synaptic changes of cell type- and projectionspecific dopaminergic transmission at the different stages of sleep-wake cycles $[105,106]$. Of course, given the modest DA release associated with sleep-wake cycles [106], the next generation of DA sensors with improved fluorescence responses may be required to dissect the synaptic dopaminergic mechanisms underlying sleep-wake behaviors.

In summary, genetically encoded sensors have made the experimental verification of the aforementioned hypotheses and possibilities feasible in various disease models. With the human pluripotent stem cell (iPSC) technologies, the diseases models can extend to healthy and diseased human iPSC-derived neuron preparations [112-114]. A pioneering investigation has shown that fast transmission between human iPSC-differentiated neurons behave similarly as that between rodent neurons, with their synaptic properties sharing comparable numerical parameters [115]. This inspired us to express genetically encoded sensors in human cholinergic and monoaminergic neuron culture preparations (Fig. 4A), which are applicable for interrogation of neuromodulatory transmission among human neurons and non-neuronal cells $[29,32,114]$. Micro- and nano-scopic image analysis showed that neuromodulatory transmission in human neuron culture preparations exhibited fine regulation and precision (Fig. 4B-D), reminiscent of that in rodent brain slice and in vivo preparations [29, 32]. These preliminary experiments establish a human-induced neuron system to define synaptic parameters of healthy human neuromodulatory transmission, delineate deficits of diseased human neuromodulatory transmission, screen therapeutic drugs and disease-causing genes, and develop potential cell transplantation-based therapies, raising exciting possibilities for regenerative and personalized medicines. 


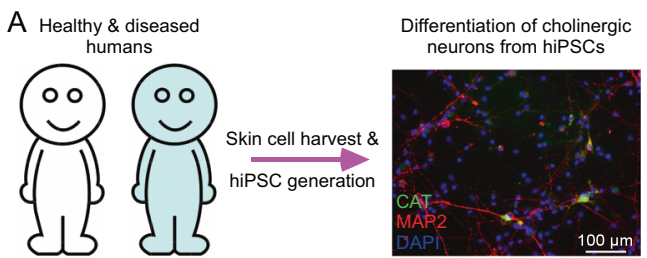

C

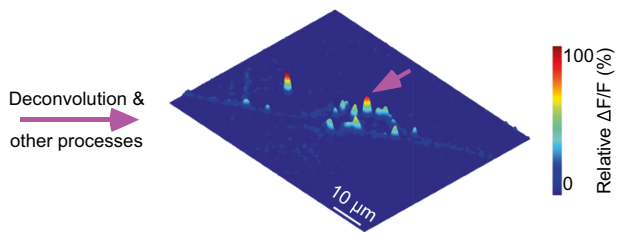

Fig. 4 Visualization of human cholinergic transmission with iAChSnFR. A Schematic of the differentiation of cholinergic neurons from human-induced pluripotent stem cells (hiPSCs). CAT anticholine acetyltransferase staining (Abcam, \#ab223346), MAP2 antimicrotubule-associated protein 2 staining (Abcam, \#ab32454), DAPI 4',6-diamidino-2-phenylindole nucleic acid staining (Sigma-Aldrich, D9542). Note the authentication of hiPSCs in the previous report [67]. B Imaging fluorescence responses of an iAChSnFR expressing human iPSC-derived neuron evoked by a train of 20 stimulating pulses

Acknowledgements We thank members of the Zhu laboratory for comments and discussions, Peng Zhang, Yajun Zhang, and Roger Zhu for assistance in data collection and analysis, and Drs. Henry Lester, Yulong Li, Loren Looger, Zhiping Pan, and Lin Tian for sharing unpublished sensors and information.

Author contributions JJZ conceived the neurotransmitter sensorbased superresolution and deconvolution microscopic analysis method, and supervised the method development with input from LL and KS; SG, WSZ, and JJZ performed the experiments and/or analysis; JJZ and LL wrote the manuscript with input from the other co-authors.

\section{Compliance with ethical standards}

Conflict of interest The authors declare that they have no conflict of interest.

Publisher's note Springer Nature remains neutral with regard to jurisdictional claims in published maps and institutional affiliations.

Open Access This article is licensed under a Creative Commons Attribution 4.0 International License, which permits use, sharing, adaptation, distribution and reproduction in any medium or format, as long as you give appropriate credit to the original author(s) and the source, provide a link to the Creative Commons license, and indicate if changes were made. The images or other third party material in this article are included in the article's Creative Commons license, unless indicated otherwise in a credit line to the material. If material is not included in the article's Creative Commons license and your intended use is not permitted by statutory regulation or exceeds the permitted use, you will need to obtain permission directly from the copyright holder. To view a copy of this license, visit http://creativecommons. org/licenses/by/4.0/.

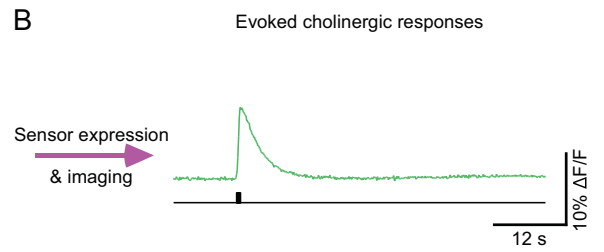

D

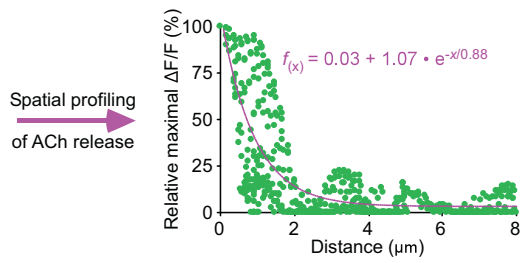

delivered at $32 \mathrm{~Hz}$. C Deconvolution microscopic analysis of threedimensional spatiotemporal $\Delta \mathrm{F} / \mathrm{F}$ profiling of the iAChSnFR expressing human iPSC-derived neuron to local electrical stimuli. Note one isolated release site indicated by pink arrow in C. D Spatial profiling of the isolated release site indicated by the pink arrow in $\mathbf{C}$ with a pixelwise maximal $\Delta \mathrm{F} / \mathrm{F}$ plot. Fitting the data points in this plot with a single exponential decay function (pink line) yields an estimated $\mathrm{ACh}$ spread length constant of $0.88 \mu \mathrm{m}$.

\section{References}

1. Volk L, Chiu SL, Sharma K, Huganir RL. Glutamate synapses in human cognitive disorders. Annu Rev Neurosci. 2015;38:127-49.

2. Bayes A, van de Lagemaat LN, Collins MO, Croning MD, Whittle IR, Choudhary JS, et al. Characterization of the proteome, diseases and evolution of the human postsynaptic density. Nat Neurosci. 2011;14:19-21.

3. Sudhof TC. Towards an understanding of synapse formation. Neuron. 2018;100:276-93.

4. Henley JM, Wilkinson KA. Synaptic AMPA receptor composition in development, plasticity and disease. Nat Rev Neurosci. 2016;17:337-50.

5. Ballinger EC, Ananth M, Talmage DA, Role LW. Basal forebrain cholinergic circuits and signaling in cognition and cognitive decline. Neuron. 2016;91:1199-218.

6. Picciotto MR, Higley MJ, Mineur YS. Acetylcholine as a neuromodulator: cholinergic signaling shapes nervous system function and behavior. Neuron. 2012;76:116-29.

7. Ravindran LN, Stein MB. The pharmacologic treatment of anxiety disorders: a review of progress. J Clin psychiatry. 2010;71:839-54.

8. Maia TV, Frank MJ. From reinforcement learning models to psychiatric and neurological disorders. Nat Neurosci. 2011;14:154-62.

9. Jacob SN, Nienborg H. Monoaminergic neuromodulation of sensory processing. Front Neural Circuits. 2018;12:51.

10. Volkow ND, Michaelides M, Baler R. The neuroscience of drug reward and addiction. Physiological Rev. 2019;99:2115-40.

11. Neher E. Merits and limitations of vesicle pool models in view of heterogeneous populations of synaptic vesicles. Neuron. 2015;87:1131-42.

12. Jackman SL, Regehr WG. The mechanisms and functions of synaptic facilitation. Neuron. 2017;94:447-64. 
13. Dani JA, Bertrand D. Nicotinic acetylcholine receptors and nicotinic cholinergic mechanisms of the central nervous system. Annu Rev Pharmacol Toxicol. 2007;47:699-729.

14. Nadim F, Bucher D. Neuromodulation of neurons and synapses. Curr Opin Neurobiol. 2014;29:48-56.

15. Olive MF, Mehmert KK, Hodge CW. Microdialysis in the mouse nucleus accumbens: a method for detection of monoamine and amino acid neurotransmitters with simultaneous assessment of locomotor activity. Brain Res Protoc. 2000;5:16-24.

16. Darvesh AS, Carroll RT, Geldenhuys WJ, Gudelsky GA, Klein $\mathrm{J}$, Meshul CK, et al. In vivo brain microdialysis: advances in neuropsychopharmacology and drug discovery. Expert Opin Drug Dis. 2011;6:109-27.

17. Robinson DL, Hermans A, Seipel AT, Wightman RM. Monitoring rapid chemical communication in the brain. Chem Rev. 2008;108:2554-84.

18. Muller A, Joseph V, Slesinger PA, Kleinfeld D. Cell-based reporters reveal in vivo dynamics of dopamine and norepinephrine release in murine cortex. Nat Methods. 2014;11:1245-52.

19. Vilardaga JP, Bunemann M, Krasel C, Castro M, Lohse MJ. Measurement of the millisecond activation switch of $\mathrm{G}$ proteincoupled receptors in living cells. Nat Biotechnol. 2003;21:807-12.

20. Wang W, Kim CK, Ting AY. Molecular tools for imaging and recording neuronal activity. Nat Chem Biol. 2019;15:101-10.

21. Lin MZ, Schnitzer MJ. Genetically encoded indicators of neuronal activity. Nat Neurosci. 2016;19:1142-53.

22. Wang $\mathrm{H}$, Jing $\mathrm{M}, \mathrm{Li} \mathrm{Y}$. Lighting up the brain: genetically encoded fluorescent sensors for imaging neurotransmitters and neuromodulators. Curr Opin Neurobiol. 2018;50:171-8.

23. Andreoni A, Davis CMO, Tian L. Measuring brain chemistry using genetically encoded fluorescent sensors. Curr Opin Biomed Eng. 2019;12:59-67.

24. Jing M, Zhang P, Wang G, Feng J, Mesik L, Zeng J, et al. A genetically encoded fluorescent acetylcholine indicator for in vitro and in vivo studies. Nat Biotechnol. 2018;36:726-37.

25. Sun FM, Zeng JZ, Jing M, Zhou JH, Feng JS, Owen SF, et al. A genetically encoded fluorescent sensor enables rapid and specific detection of dopamine in flies, fish, and mice. Cell. 2018;174:481-96.

26. Patriarchi T, Cho JR, Merten K, Howe MW, Marley A, Xiong $\mathrm{WH}$, et al. Ultrafast neuronal imaging of dopamine dynamics with designed genetically encoded sensors. Science. 2018;360: eaat4422.

27. Marvin JS, Borghuis BG, Tian L, Cichon J, Harnett MT, Akerboom J, et al. An optimized fluorescent probe for visualizing glutamate neurotransmission. Nat Methods. 2013;10:162-70.

28. Helassa N, Durst CD, Coates C, Kerruth S, Arif U, Schulze C, et al. Ultrafast glutamate sensors resolve high-frequency release at Schaffer collateral synapses. Proc Natl Acad Sci USA. 2018;115:5594-9.

29. Borden PM, Zhang P, Shivange AV, Marvin JS, Cichon J, Dan $\mathrm{C}$, et al. A fast genetically encoded fluorescent sensor for faithful in vivo acetylcholine detection in mice, fish, worms and flies. bioRxiv. 2020. https://doi.org/10.1101/2020.02.07.939504.

30. Marvin JS, Scholl B, Wilson DE, Podgorski K, Kazemipour A, Muller JA, et al. Stability, affinity, and chromatic variants of the glutamate sensor iGluSnFR. Nat Methods. 2018;15:936-9.

31. Jing M, Li Y, Zeng J, Huang P, Skirzewski M, Kljakic O, et al. An optimized acetylcholine sensor for monitoring in vivo cholinergic activity. Nat Methods. 2020;17:1139-46.

32. Zhu PK, Zheng WS, Zhang P, Jing M, Borden PM, Ali F, et al. Nanoscopic visualization of restricted non-volume cholinergic and monoaminergic transmission with genetically encoded sensors. Nano Lett. 2020;20:4073-83.

33. Feng J, Zhang C, Lischinsky JE, Jing M, Zhou J, Wang H, et al. A genetically encoded fluorescent sensor for rapid and specific in vivo detection of norepinephrine. Neuron. 2019;102:745-61. e748.

34. Wan J, Peng W, Li X, Qian T, Song K, Zeng J, et al. A genetically encoded GRAB sensor for measuring serotonin dynamics in vivo. bioRxiv. 2020. https://doi.org/10.1101/2020. 02.24.962282.

35. Unger EK, Keller JP, Altermatt M, Liang P, Yao Z, Sun J, et al. Directed evolution of a selective and sensitive serotonin biosensor via machine learning. 2020. https://papers.ssrn.com/sol3/ papers.cfm?abstract_id $=3498571$.

36. Sun FM, Zhou J, Dai B, Qian T, Zeng J, Li X, et al. Nextgeneration GRAB sensors for monitoring dopaminergic activity in vivo. Nat Methods. 2020;17:1156-66.

37. Patriarchi T, Cho JR, Merten K, Marley A, Broussard GJ, Liang $\mathrm{R}$, et al. Imaging neuromodulators with high spatiotemporal resolution using genetically encoded indicators. Nat Protoc. 2019;14:3471-505

38. Lutas A, Kucukdereli H, Alturkistani O, Carty C, Sugden AU, Fernando K, et al. State-specific gating of salient cues by midbrain dopaminergic input to basal amygdala. Nat Neurosci. 2019;22:1820-33.

39. Bjorklund A, Dunnett SB. Dopamine neuron systems in the brain: an update. Trends Neurosci. 2007;30:194-202.

40. Morales M, Margolis EB. Ventral tegmental area: cellular heterogeneity, connectivity and behaviour. Nat Rev Neurosci. 2017;18:73-85.

41. Patriarchi T, Mohebi A, Sun J, Marley A, Liang R, Dong C, et al. An expanded palette of dopamine sensors for multiplex imaging in vivo. Nat Methods. 2020;17:1147-55.

42. Jing M, Zhang Y, Wang H, Li Y. G-protein-coupled receptorbased sensors for imaging neurochemicals with high sensitivity and specificity. J Neurochem. 2019;151:279-88.

43. Sabatini BL, Tian L. Imaging neurotransmitter and neuromodulator dynamics in vivo with genetically encoded indicators. Neuron. 2020;108:17-32.

44. Guo M, Li Y, Su Y, Lambert T, Nogare DD, Moyle MW, et al. Rapid image deconvolution and multiview fusion for optical microscopy. Nat Biotechnol. 2020;38:1337-46.

45. Schermelleh L, Ferrand A, Huser T, Eggeling C, Sauer M, Biehlmaier O, et al. Super-resolution microscopy demystified. Nat Cell Biol. 2019;21:72-84.

46. Wang G, Zhang P, Mendu SK, Wang Y, Zhang Y, Kang X, et al. Revaluation of magnetic properties of Magneto. Nat Neurosci. 2019;23:1047-50.

47. Meister M. Physical limits to magnetogenetics. eLife. 2016;5: e17210.

48. Volkmann H. Ernst abbe and his work. Appl Opt. 1966;5:1720-31.

49. Abbe E. Beiträge zur Theorie des Mikroskops und der mikroskopischen Wahrnehmung. Ark Mikrosk Anat. 1873;9:413-68.

50. Francia GTD. Super-gain antennas and optical resolving power. Nuovo Cim Suppl. 1952;9:426-38.

51. Lukosz W. Optical systems with resolving powers exceeding classical limit. J Opt Soc Am. 1966;56:1463-71.

52. Bechhoefer J. What is superresolution microscopy? Am J Phys. 2015;83:22-29.

53. Weigert M, Schmidt U, Boothe T, Muller A, Dibrov A, Jain A, et al. Content-aware image restoration: pushing the limits of fluorescence microscopy. Nat Methods. 2018;15:1090-7.

54. Hell SW. Far-field optical nanoscopy. Science. 2007;316:1153-8. 
55. Arigovindan M, Fung JC, Elnatan D, Mennella V, Chan YH, Pollard M, et al. High-resolution restoration of 3D structures from widefield images with extreme low signal-to-noise-ratio. Proc Natl Acad Sci USA. 2013;110:17344-9.

56. Koho S, Tortarolo G, Castello M, Deguchi T, Diaspro A, Vicidomini G. Fourier ring correlation simplifies image restoration in fluorescence microscopy. Nat Commun. 2019;10:3103.

57. Mukamel EA, Babcock H, Zhuang X. Statistical deconvolution for superresolution fluorescence microscopy. Biophys $\mathrm{J}$. 2012;102:2391-400.

58. Preibisch S, Amat F, Stamataki E, Sarov M, Singer RH, Myers E, et al. Efficient Bayesian-based multiview deconvolution. Nat Methods. 2014;11:645-8.

59. Pulido C, Marty A. Quantal fluctuations in central mammalian synapses: functional role of vesicular docking sites. Physiological Rev. 2017;97:1403-30.

60. Malinow R, Hayashi Y, Maletic-Savatic M, Zaman SH, Poncer $\mathrm{JC}$, Shi SH, et al. Introduction of green fluorescent protein (GFP) into hippocampal neurons through viral infection. Cold Spring Harb Protoc. 2010;2010:pdb prot5406.

61. Uyaniker S, van der Spek SJF, Reinders NR, Xiong H, Li KW, Bossers $\mathrm{K}$, et al. The effects of sindbis viral vectors on neuronal function. Front Cell Neurosci. 2019;13:362.

62. Zhang L, Zhang P, Wang G, Zhang H, Zhang Y, Yu Y, et al. Ras and Rap signal bidirectional synaptic plasticity via distinct subcellular microdomains. Neuron. 2018;98:783-800.

63. Samulski RJ, Muzyczka N. AAV-mediated gene therapy for research and therapeutic purposes. Annu Rev Virol. 2014;1:427-51.

64. Wang D, Tai PWL, Gao G. Adeno-associated virus vector as a platform for gene therapy delivery. Nat Rev Drug Discov. 2019;18:358-78.

65. Matrai J, Chuah MK, VandenDriessche T. Recent advances in lentiviral vector development and applications. Mol Ther. 2010;18:477-90.

66. Alfranca A, Campanero MR, Redondo JM. New methods for disease modeling using lentiviral vectors. Trends Mol Med. 2018;24:825-37.

67. Lim CS, Kang X, Mirabella V, Zhang H, Bu Q, Araki Y, et al. BRaf signaling principles unveiled by large-scale human mutation analysis with a rapid lentivirus-based gene replacement method. Genes Dev. 2017;31:537-52.

68. Jiang X, Wang G, Lee AJ, Stornetta RL, Zhu JJ. The organization of two new cortical interneuronal circuits. Nat Neurosci. 2013;16:210-8.

69. Zhu JJ. Activity level-dependent synapse-specific AMPA receptor trafficking regulates transmission kinetics. J Neurosci. 2009;29:6320-35.

70. Wang G, Wyskiel DR, Yang W, Wang Y, Milbern LC, Lalanne $\mathrm{T}$, et al. An optogenetics- and imaging-assisted simultaneous multiple patch-clamp recordings system for decoding complex neural circuits. Nat Protoc. 2015;10:397-412.

71. Sibarita JB. Deconvolution microscopy. Adv Biochem Eng Biotechnol. 2005;95:201-43.

72. Barbour B, Hausser M. Intersynaptic diffusion of neurotransmitter. Trends Neurosci. 1997;20:377-84.

73. Sarter M, Parikh V, Howe WM. Phasic acetylcholine release and the volume transmission hypothesis: time to move on. Nat Rev Neurosci. 2009;10:383-90.

74. Agnati LF, Bjelke B, Fuxe K. Volume transmission in the brain. Am Sci. 1992;80:362-73.

75. Zoli M, Jansson A, Sykova E, Agnati LF, Fuxe K. Volume transmission in the CNS and its relevance for neuropsychopharmacology. Trends Pharmacol Sci. 1999;20:142-50.

76. Borroto-Escuela DO, Perez De La Mora M, Manger P, Narvaez M, Beggiato S, Crespo-Ramirez M, et al. Brain dopamine transmission in health and Parkinson's disease: modulation of synaptic transmission and olasticity through volume transmission and dopamine heteroreceptors. Front Synaptic Neurosci. 2018; $10: 20$

77. Beckstead MJ, Grandy DK, Wickman K, Williams JT. Vesicular dopamine release elicits an inhibitory postsynaptic current in midbrain dopamine neurons. Neuron. 2004;42:939-46.

78. Courtney NA, Ford CP. The timing of dopamine- and noradrenaline-mediated transmission reflects underlying differences in the extent of spillover and pooling. J Neurosci. 2014;34:7645-56.

79. Courtney NA, Ford CP. Mechanisms of 5-HT1A receptormediated transmission in dorsal raphe serotonin neurons. J Physiol. 2016;594:953-65.

80. Jensen TP, Zheng K, Cole N, Marvin JS, Looger LL, Rusakov DA. Multiplex imaging relates quantal glutamate release to presynaptic $\mathrm{Ca}^{2+}$ homeostasis at multiple synapses in situ. Nat Commun. 2019;10:1414.

81. Sylantyev S, Savtchenko LP, Niu YP, Ivanov AI, Jensen TP, Kullmann DM, et al. Electric fields due to synaptic currents sharpen excitatory transmission. Science. 2008;319:1845-9.

82. Savtchenko LP, Sylantyev S, Rusakov DA. Central synapses release a resource-efficient amount of glutamate. Nat Neurosci. 2013;16:10-12.

83. Savtchenko LP, Rusakov DA. The optimal height of the synaptic cleft. Proc Natl Acad Sci USA. 2007;104:1823-8.

84. Haas KT, Compans B, Letellier M, Bartol TM, Grillo-Bosch D, Sejnowski TJ, et al. Pre-post synaptic alignment through neuroligin-1 tunes synaptic transmission efficiency. eLife. 2018;7:e31755. https://doi.org/10.7554/eLife.31755.001.

85. Schneggenburger R, Meyer AC, Neher E. Released fraction and total size of a pool of immediately available transmitter quanta at a calyx synapse. Neuron. 1999;23:399-409.

86. Thanawala MS, Regehr WG. Presynaptic calcium influx controls neurotransmitter release in part by regulating the effective size of the readily releasable pool. J Neurosci. 2013;33:4625-33.

87. Elmqvist D, Quastel DM. A quantitative study of end-plate potentials in isolated human muscle. $\mathrm{J}$ Physiol. 1965;178:505-29.

88. Ruiz R, Cano R, Casanas JJ, Gaffield MA, Betz WJ, Tabares L. Active zones and the readily releasable pool of synaptic vesicles at the neuromuscular junction of the mouse. J Neurosci. 2011;31:2000-8.

89. Mash DC, Flynn DD, Potter LT. Loss of $\mathrm{M}_{2}$ muscarine receptors in the cerebral cortex in Alzheimer's disease and experimental cholinergic denervation. Science. 1985;228:1115-7.

90. Zemek F, Drtinova L, Nepovimova E, Sepsova V, Korabecny J, Klimes J, et al. Outcomes of Alzheimer's disease therapy with acetylcholinesterase inhibitors and memantine. Expert Opin Drug Saf. 2014;13:759-74.

91. Ashford JW. Treatment of Alzheimer's disease: the legacy of the cholinergic hypothesis, neuroplasticity, and future directions. J Alzheimer's Dis. 2015;47:149-56.

92. Simic G, Leko MB, Wray S, Harrington CR, Delalle I, JovanovMilosevic N, et al. Monoaminergic neuropathology in Alzheimer's disease. Prog Neurobiol. 2017;151:101-38.

93. Mather M, Harley CW. The locus coeruleus: essential for maintaining cognitive function and the aging brain. Trends Cogn Sci. 2016;20:214-26.

94. Carter ME, Yizhar O, Chikahisa S, Nguyen H, Adamantidis A, Nishino $S$, et al. Tuning arousal with optogenetic modulation of locus coeruleus neurons. Nat Neurosci. 2010;13:1526-33.

95. Gompf HS, Mathai C, Fuller PM, Wood DA, Pedersen NP, Saper CB, et al. Locus ceruleus and anterior cingulate cortex sustain wakefulness in a novel environment. J Neurosci. 2010;30:14543-51. 
96. McKhann GM, Knopman DS, Chertkow H, Hyman BT, Jack CR Jr., Kawas $\mathrm{CH}$, et al. The diagnosis of dementia due to Alzheimer's disease: recommendations from the National Institute on Aging-Alzheimer's Association workgroups on diagnostic guidelines for Alzheimer's disease. Alzheimer's Dement. 2011;7:263-9.

97. Nestler EJ, Luscher C. The molecular basis of drug addiction: linking epigenetic to synaptic and circuit mechanisms. Neuron. 2019;102:48-59.

98. Mohebi A, Pettibone JR, Hamid AA, Wong JT, Vinson LT, Patriarchi T, et al. Dissociable dopamine dynamics for learning and motivation. Nature. 2019;570:65-70.

99. Krishnan V, Nestler EJ. The molecular neurobiology of depression. Nature. 2008;455:894-902.

100. Gold PW. The organization of the stress system and its dysregulation in depressive illness. Mol Psychiatry. 2015;20:32-47.

101. Gururajan A, Reif A, Cryan JF, Slattery DA. The future of rodent models in depression research. Nat Rev Neurosci. 2019;20:686-701.

102. Schildkraut JJ. The catecholamine hypothesis of affective disorders: a review of supporting evidence. Am J Psychiatry. 1965;122:509-22.

103. Hu H, Cui Y, Yang Y. Circuits and functions of the lateral habenula in health and in disease. Nat Rev Neurosci. 2020;21:277-95.

104. Okaty BW, Commons KG, Dymecki SM. Embracing diversity in the 5-HT neuronal system. Nat Rev Neurosci. 2019;20:397-424.

105. Scammell TE, Arrigoni E, Lipton JO. Neural circuitry of wakefulness and sleep. Neuron. 2017;93:747-65.
106. Eban-Rothschild A, Appelbaum L, de Lecea L. Neuronal mechanisms for sleep/wake regulation and modulatory drive. Neuropsychopharmacology. 2018;43:937-52.

107. Weber F, Dan Y. Circuit-based interrogation of sleep control. Nature. 2016;538:51-59.

108. Buzsaki G, Bickford RG, Ponomareff G, Thal LJ, Mandel R, Gage FH. Nucleus basalis and thalamic control of neocortical activity in the freely moving rat. J Neurosci. 1988;8:4007-26.

109. Fuller PM, Sherman D, Pedersen NP, Saper CB, Lu J. Reassessment of the structural basis of the ascending arousal system. J Comp Neurol. 2011;519:933-56.

110. Rial RV, Canellas F, Gamundi A, Akaarir M, Nicolau MC. Pleasure: the missing link in the regulation of sleep. Neurosci Biobehav Rev. 2018;88:141-54.

111. Korshunov KS, Blakemore LJ, Trombley PQ. Dopamine: a modulator of circadian rhythms in the central nervous system. Front Cell Neurosci. 2017;11:91.

112. Soldner F, Jaenisch R. Stem cells, genome editing, and the path to translational medicine. Cell. 2018;175:615-32.

113. Rowe RG, Daley GQ. Induced pluripotent stem cells in disease modelling and drug discovery. Nat Rev Genet. 2019;20:377-88.

114. Penney J, Ralvenius WT, Tsai LH. Modeling Alzheimer's disease with iPSC-derived brain cells. Mol Psychiatry. 2020;25:148-67.

115. Patzke C, Brockmann MM, Dai J, Gan KJ, Grauel MK, Fenske P, et al. Neuromodulator signaling bidirectionally controls vesicle numbers in human synapses. Cell. 2019;179:498-513. e422. 